Article

\title{
Moderating effects of organizational commitment on job satisfaction and turnover intention
}

\author{
Hassan Wazir ${ }^{1}$, and Inayatullah Jan ${ }^{2 *}$ \\ 1 Institute of Business and Management Sciences (IBMS), The University of Agriculture Peshawar, Pakistan; \\ hassanwazir@yahoo.com \\ 2 Institute of Development Studies (IDS), The University of Agriculture Peshawar, Pakistan; \\ jaan.inayat43@gmail.com \\ * Correspondence:jaan.inayat@gmail.com; Tel:+ 923005956780
}

Received: 4 July 2020; Accepted: 24 September 2020; Published: 30 September 2020

\begin{abstract}
This study was conducted in Bannu, Karak, Lakki Marwat, and D.I. Khan Districts of Khyber Pakhtunkhwa (KP) Province of Pakistan to investigate the relationship between job satisfaction and turnover intention. The study is based on data collected from Wateen and Multinet Telecom companies. Two staged-sampling technique was used in this study. A total of 140 employees were selected from both companies using equal allocation and stratified random sampling techniques. A structured questionnaire with a five-point Likert scale was used to collect information from respondents. Regression analysis was used to find out the relationship between job satisfaction and turnover intention. The results of the regression model indicated that job satisfaction decreases the chances of turnover. The results also confirmed that organizational commitment plays a key mediating role in improving job satisfaction and reducing turnover intentions. The study recommends that organizations should make efforts to promote job satisfaction to enhance organizational commitment and reduce turnover.
\end{abstract}

Keywords: Job satisfaction; Organizational commitment; Turnover intention; Telecommunication; Regression analysis.

JEL codes: J28; J63; D23; L96

\section{Introduction}

Organizations invest time and money on recruitment and selection, training and development, employees' commitment, and service and product quality so that to achieve competitive human resource advantages (Hayes et al., 2006; Griffeth et al., 2000). However, employees' turnover adversely affects organizational effectiveness and performance. Therefore, effective managers always investigate the causes of turnover and seek to resolve them to retain their best employees. Yet, employees' turnover is common in organizations for many reasons.

Because of the nature of the problem and its immediate effects on organizational performance, researchers have made frequent attempts to explore the factors behind employees' turnover. Different researchers have reported different reasons for employees' turnover. For instance, Cotton \& Tuttle (1986) have classified those factors into three types, viz., work-related factors (e.g. job satisfaction, pay structure, self-performance, organizational commitment, and others), personal factors (e.g. age, education, gender, job tenure, and others and external factors (e.g. unemployment rate, employment perceptions, labor union in an organization, and others.

Job satisfaction (Locke, 1976) and organizational commitment (Cotton \& Tuttle, 1986) are considered as the most important factors to reduce turnover and increase organizational competitive 
advantage. They also result in increased productivity of an organization. Hence, job satisfaction and organizational commitment are the most studied topics in the work-related issues of turnover (Foreman, 2009). Literature shows that job satisfaction significantly lowers employees' turnover (Foreman, 2009). Besides, organizational commitment buffers the relationship between job satisfaction and turnover (Tubay, 2019). Low job security or organizational commitment increases turnover and vice versa (Kinicki et al., 2002).

There are some facets or elements which lead to the job satisfaction of an employee. However, even one facet of the job such as promotion, pay, recognition, appreciation, coworkers, security, or supervision can have a great impact on the overall job satisfaction level (Locke, 1976). This study uses the facet model of job satisfaction to measure the job satisfaction level of employees in the sampled companies.

As a result of technological advancement and the fast-growing telecommunication sector, people can record and send messages instantly through online banking, e-commerce, internet, and social websites. Many companies in Pakistan provide telecommunication services. This study, however, focuses only on the optical fiber provider companies. The main reason to select telecommunication companies is that these companies face tough competition to retain their best employees because of the fast-growing market, less availability of technically sound staff, migration of the skilled workers to other countries. This competition becomes more complex in smaller cities as in the case of the research districts.

\subsection{Rationale of the Study}

Pakistan is a country having low per capita income with a lower level of literacy rate and skilled manpower. A very large number of educated and skilled youth emigrate to foreign countries for better employment opportunities and high wages in those countries. In such circumstances, telecommunication companies, like other sectors, face it challenging to retain their best employees for three reasons. This competition becomes more complex in the case of small cities where companies face frequent problems with employees' turnover. Employees' turnover can be minimized if employees are more satisfied with their job. Therefore, identifying the reasons for employees' job satisfaction and the relationship between job satisfaction and turnover is important.

In Pakistan, there are three major optical fiber providing companies namely, Pakistan Telecommunication Limited (PTCL), Wateen Telecom, and Multinet Telecom. As far as PTCL is concerned, many studies can be found in this company. However, Wateen Telecom and Multinet Telecom are relatively new, and therefore, little empirical evidence can be found about the relationship between job satisfaction and turnover exemplifying these companies. Therefore, this study is carried out to identify the relationship between job satisfaction and turnover and also to find out the moderating role of organizational commitment in the optical fiber provider Telecommunication companies in Pakistan. The findings of the study would help the management of such companies to take pro-workers measures to increase job satisfaction, organizational commitment level, and reduce turnover.

\subsection{Objectives and Hypotheses}

This study has been designed with the main objective to find out the relationship between job satisfaction and turnover in the afore-mentioned companies. The null hypotheses $\left(\mathrm{H}_{0}\right)$ of the study are that there is no significant relationship between job satisfaction and turnover and that organizational commitment is not significantly moderating the relationship between job satisfaction and turnover.

\section{Literature Review and Theoretical Framework}

The theoretical framework of the study is that job satisfaction reduces turnover intention and vice versa. Organizational commitment plays a key moderating role in the relationship between job 
satisfaction and turnover intention. The theoretical framework of the study, which explains all the variables which are used in the study and their relationship with each other, is illustrated as follows.

Figure 1. Theoretical Framework of the Study.

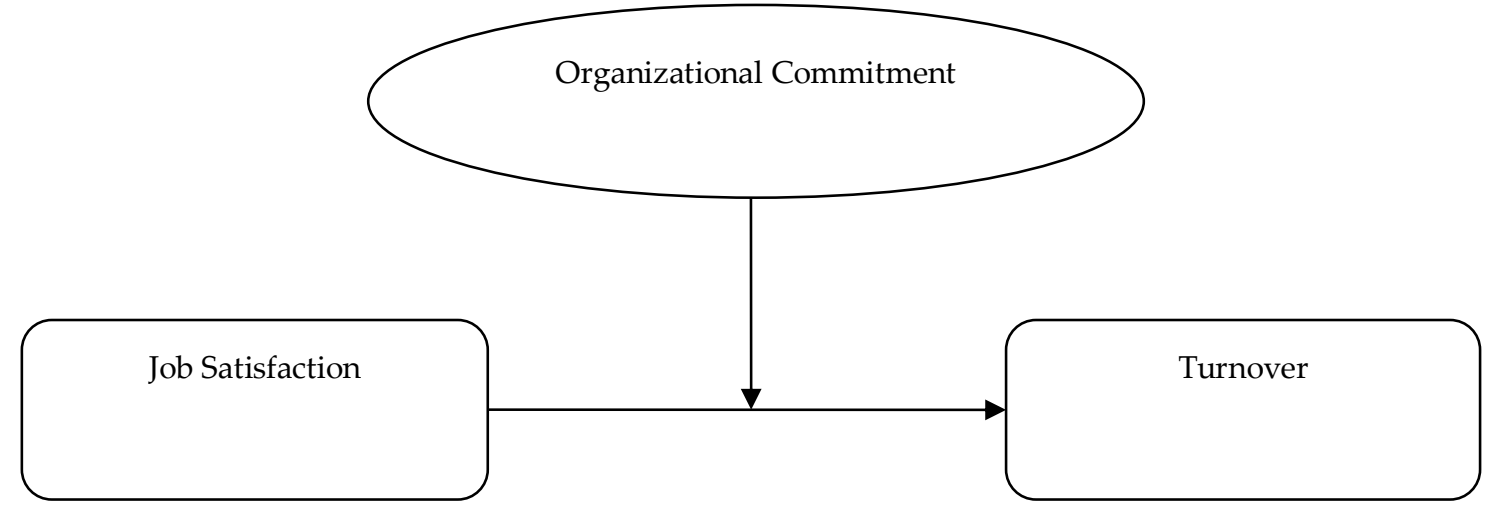

Source: Own depiction

Recent literature provides empirical evidence of the relationship between job satisfaction, organizational commitment, and turnover. For example, Ali (2009) researched the relationship of job satisfaction with turnover. The results showed that private-sector teachers were dissatisfied with promotion chances, moderately dissatisfied with pay, benefits, contingent rewards, and moderately satisfied with operating conditions, coworkers, nature of work, and communication. All job satisfaction factors were found significantly associated with turnover intention, but turnover had the highest correlation with pay, promotion, fringe benefits, and contingent rewards.

In another study, Kaplan (2009) researched on the determinants of job satisfaction and turnover intention. Results indicated that job satisfaction of the employees was related to their perception of autonomy, workload, work-life, private life conflict, pay, and community satisfaction. Furthermore, all the independent variables except workload had a relationship with turnover intention.

Similarly, Mudor \& Tooksoon (2011) researched the relationship between human resource management practice (supervision, job training, and pay), job satisfaction, and turnover. The results showed a strong positive relationship between job satisfaction and human resource management practice whereas the relationship of both job satisfaction and human resource management practice with turnover was found significantly negative. They suggested an increase in job satisfaction to decrease turnover. Ahmad et al., (2012) used Pearson correlation and multiple regression analysis and identified that job satisfaction and job stress have a significantly negative relationship with turnover in the textile sector in Pakistan.

Hung et al., (2018) investigated the effects of organizational climate, organizational commitment, and turnover intention of 771 life insurance personnel in Taiwan. They reported that organizational climate and organizational commitment harmed employee turnover. Furthermore, the organizational climate had a positive effect on organizational commitment. They reported that the mediating role of organizational climate and organizational commitment significantly affect the turnover intention.

Obiechina (2019) conducted a moderation analysis of the constituent attachment on the relationship between organizational commitment and turnover intention of employees in an IT firm in Bangkok. The findings suggested that organizational commitment has a negative relationship with turnover intention and that the constituent attachment does not moderate the relationship. This implies that organizational commitment decreases the chances of employee turnover and vice versa.

In another study, Tubay (2019) examined whether job satisfaction and organizational commitment would determine the turnover intentions, and the moderating role by leader-member exchange (LMX), of accountants working in auditing firms in the Philippines. Using the regression model, the study depicted that extrinsic job satisfaction has a significant negative effect on turnover intentions. LMX on the other hand moderated the effect of commitment on turnover intentions. 
Wang \& Wang (2020) studied the effect of perceived organizational support (POS) on burnout and turnover intention in China. Based on data from the employees of a gas station in Beijing, they studied the mediating effects of employee burnout on their POS and turnover intention. This study shows that POS has a significant negative impact on burnout and turnover intention.

Lin \& Huang (2020) conducted a study to investigate the relationships among an organizational learning culture (OLC), job satisfaction, turnover intentions, and job performance in a telecommunications company in Taiwan. Using structural equation modeling (SEM) and bootstrapping estimation, the study found that job satisfaction hurt employee turnover intentions but a positive impact on job performance. They also reported that job satisfaction fully mediated the relationships between OLC and employee turnover intentions and job performance.

Romeo et al., (2020) explored the effects of job satisfaction on turnover of employees with disability and the mediating role of organizational commitment of employees in special employment centers in Spain. Using bivariate correlations, the study found that job satisfaction has a positive significant relationship with turnover intentions. However, organizational commitment has no significant moderating role between job satisfaction and employee turnover.

The above literature suggests that job satisfaction and turnover are strongly and inversely related and organizational performance has a mediating role in enhancing job satisfaction and reducing turnover.

\section{Methodology}

\subsection{Sampling and Data}

This study was conducted in Wateen Telecom and Multinet Telecom in Bannu, Karak, Lakki Marwat, and Dera Ismail (DI) Khan Districts of Khyber Pakhtunkhwa, Pakistan. A total of 140 employees were interviewed. The study used double staged sampling techniques. In the first stage, the equal allocation method was used to select 10 employees from each company in each district. In the second stage, a proportionate stratified random sampling procedure was used to select different cadres of employees from each company. The employees in each company were divided into different strata viz. upper management, middle management, lower management, and lower staff. In the second stage, proportionate numbers of employees were selected from each stratum through a random sampling technique. The sample includes $10 \%$ of employees from the upper management, $20 \%$ from the middle management, $30 \%$ from the lower management, and $40 \%$ from the lower staff. The inclusion of employees from all cadres ensures a fair and diverse response. Data were collected through a structured questionnaire. Close-ended questions with a response scale of items were used in the analysis. Data were analyzed using SPSS v.20.

\subsection{Variables and their Measurement}

Turnover is the dependent variable in this study which is measured as turnover intention. This study uses four items scale with a five-point Likert Scale starting from 1 (strongly disagree) to 5 (strongly agree) developed by (Foreman 2009). The independent variable of the study is job satisfaction. The study uses Minnesota Satisfaction Questionnaires developed by (Weiss et al., 1967) with a five-point Likert Scale starting from one (very dissatisfied) to five (very satisfied) to measure the job satisfaction. Besides, this study uses organizational commitment as a moderating variable. The study adapts organizational commitment questionnaires developed by Mowday et al., (1979) with a five-point Likert Scale starting from one (strongly disagree) to five (strongly agree).

\subsection{Analytical Technique}

This study uses regression analysis (Obiechina, 2019; Tubay, 2019) to confirm or possibly reject the null hypothesis that there is no significant relationship between job satisfaction and turnover and 
that organizational commitment is not significantly moderating the relationship between job satisfaction and turnover. The estimated form of the regression model is as follows.

$$
Y=\alpha+\beta_{1} X_{1}+\beta_{2} Z_{1}+\beta_{3} X_{1} Z_{1}+\varepsilon,
$$

where $Y$ is the dependent variable (Turnover), $X$ is the independent variable (Job satisfaction), $Z$ is the moderator variable (Organizational commitment), $X Z$ is the interaction of independent and moderator variable, $\beta$ s are coefficient of variables, $\alpha$ is the intercept term, and $\varepsilon$ is the error term.

\section{Results and Discussion}

\subsection{Reasons for Turnover}

Despite their continuous efforts, organizations fail to control the problem of employees' turnover. For minimizing the turnover, however, the factors that lead to turnover must be identified. Fig. 2 shows the reasons for leaving the previous organizations. The figure shows that $61 \%$ of respondents were fresh employees and had not joined any organization before. Out of the remaining, 11\% confirmed that they left the previous organizations because of low pay. The monetary gains play an important role in employees' intentions to work for an organization and low pay results in increased turnover. The workload and pays were not compatible which led to the decision to quit the previous employers. Similarly, $9 \%$ had problems with the overall structure of the organization like location, pays, promotion, and incentives and these were the main causes of leaving their organizations. Another $8 \%$ noted that they left the previous employers because of a lack of growth opportunities in their respective organizations. Similarly, the behavior of supervisors $(6 \%)$ and co-workers $(1 \%)$ were also among the important reasons identified by the respondents as the main factors behind turnover.

Figure 2. Reasons for Turnover from Previous Organization

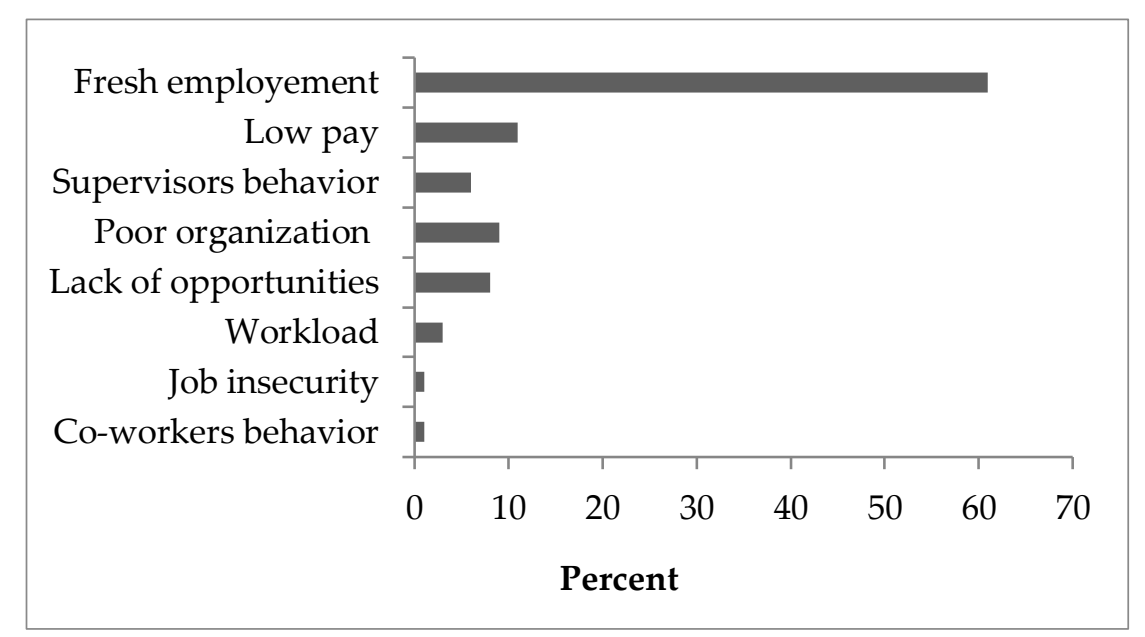

\subsection{Reasons for Joining the Current Organizations}

To collect information about the reasons for joining the current organizations help us to determine the main motivational factors (like pay, incentives, duty hours, promotion, job securities, etc.) that employees take into account while joining a new organization. These reasons are illustrated in Fig. 3. The figure shows that $35 \%$ of respondents joined these companies because of higher pay. This signifies that people keep financial gains at the utmost priority than other benefits. Similarly, $24 \%$ of respondents noted that they joined these companies because of job security. They had the perception that they were secured here and showed sensitivity to job security. Another $22 \%$ confirmed that they 
joined because of their understanding that these organizations were good in terms of their pay structure, promotion opportunities, location, repute of organization, etc. Other reasons that respondents reported were better opportunities $(9 \%)$, flexible duty hours $(5 \%)$, nature of the work in these companies $(4 \%)$, and location of the companies (1\%).

Figure 3. Reasons for Joining these Organizations

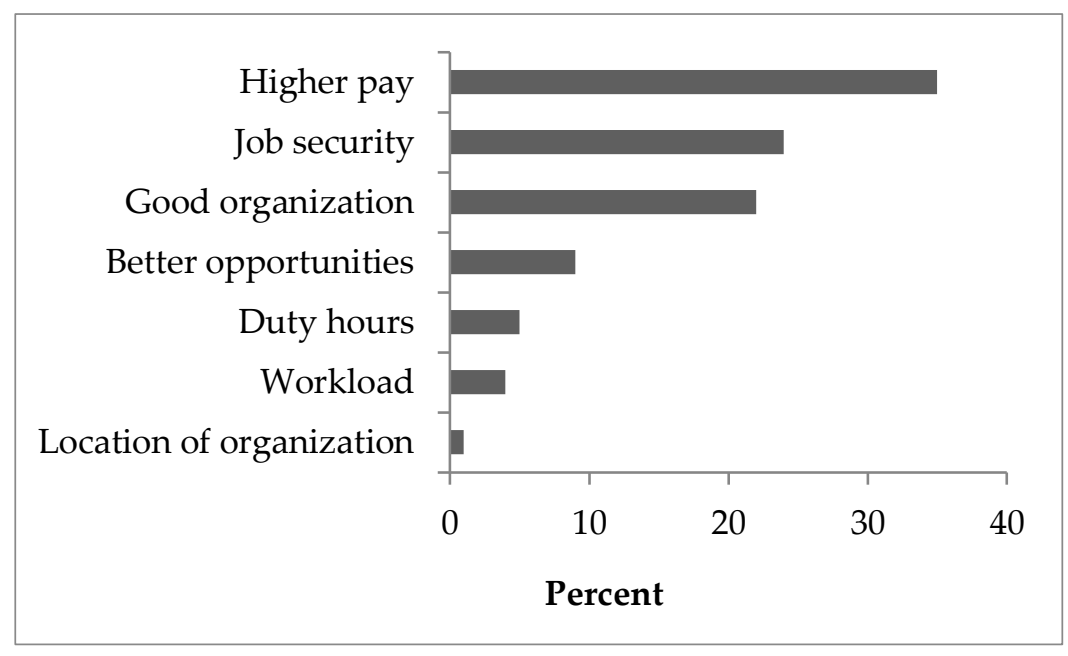

\subsection{Reliability Analysis}

The reliability of qualitative variables is determined by Cronbach's alpha. Cronbach's alpha greater than or equal to $70 \%$ is considered reliable (Hair et al., 2010). The value of Cronbach's alpha for different variables is given in Table 1 . The table shows that job satisfaction has the highest Cronbach's alpha which is $90 \%$ followed by organizational commitment $(88 \%)$ and turnover $(87 \%)$. Thus, it is confirmed that all the attributes are reliable and hence we expect some meaningful results from the data.

Table 1. Reliability Measures of Different Attributes

\begin{tabular}{ccc}
\hline Attribute & Cronbach's alpha & Remarks \\
\hline Job satisfaction & 0.90 & Reliable \\
Organizational commitment & 0.88 & Reliable \\
Turnover & 0.87 & Reliable \\
\hline
\end{tabular}

Source: Field Survey, 2013

\subsection{Perception of Job Satisfaction}

The results of the employee perception about job satisfaction are elaborated in Table 2. Each statement is related to job satisfaction. From this table, it is concluded that the maximum number of respondents agreed on the Likert scale. It also shows that some respondents remained neutral and very few of them have disagreed. Mean average score (MAS) greater than 3 or equal to 3 shows the positive perception of respondents about job satisfaction. The MAS of almost all questions remained higher than three.

The table furthers shows that $58.8 \%$ of respondents noted that they were satisfied with their performance in those organizations. Similarly, $70 \%$ of respondents agreed on the Likert scale that the attitude of the boss towards workers was positive and encouraging. This kind of positive perception of top management enhances organizational commitment and reduces turnover. For another statement on the questionnaire i.e. "the competence of supervisor in making decisions" $66.2 \%$ of respondents agreed on the Likert scale which again shows confidence in the supervisor and 
management. Respondents also recorded positive response towards their pay and working hours. A total of $43.7 \%$ of respondents noted their satisfaction with the pay and working hours. However, $35 \%$ of respondents disagreed as well which means that they were not satisfied with their pay and working hours. Most importantly, a large proportion of respondents (51.8\%) disagreed on the Likert scale to the statement about chances for growth in the current job. This negative perception could, however, reduce the level of commitment and job satisfaction and could result in increased turnover. However, another $60 \%$ recorded their satisfaction with the working conditions in the organization. Another encouraging point was that the attitude of the co-workers in the organization was also supportive and encouraging, as shown by a $53.7 \%$ response as agreed on the Liker scale. Most importantly, the majority of respondents (77.4\%) confirmed that they always got an appreciation for their good job which motivated and encouraged them. The overall MAS of 3.38 confirms a positive perception of employees about their job satisfaction which is encouraging for the smooth functioning and growth of the organizations.

Table 2. Employees' Perception Regarding Job Satisfaction

\begin{tabular}{|c|c|c|c|c|c|c|}
\hline \multirow[t]{2}{*}{ Statement } & \multicolumn{5}{|c|}{ Employee perception } & \multirow[t]{2}{*}{ MAS } \\
\hline & 1 & 2 & 3 & 4 & 5 & \\
\hline Level of satisfaction from own & 7 & 21 & 5 & 36 & 11 & 3.29 \\
\hline performance & $(8.8)$ & $(26.2)$ & $(6.2)$ & $(45)$ & $(13.8)$ & \\
\hline \multirow[t]{2}{*}{ The attitude of the boss } & 5 & 8 & 11 & 40 & 16 & 3.68 \\
\hline & $(6.2)$ & $(10)$ & $(13.8)$ & $(50)$ & $(20)$ & \\
\hline \multirow{2}{*}{$\begin{array}{l}\text { Competence of supervisor in making } \\
\text { decisions }\end{array}$} & 7 & 19 & 1 & 25 & 28 & 3.60 \\
\hline & $(8.8)$ & $(23.8)$ & $(1.2)$ & $(31.2)$ & $(35)$ & \\
\hline \multirow[t]{2}{*}{ Satisfaction with pay and work hours } & 19 & 9 & 17 & 17 & 18 & 3.08 \\
\hline & $(23.8)$ & $(11.2)$ & $(21.2)$ & $(21.2)$ & $(22.5)$ & \\
\hline \multirow[t]{2}{*}{ Chances for growth in this job } & 14 & 27 & 7 & 24 & 8 & 2.81 \\
\hline & $(17.5)$ & $(33.8)$ & $(8.8)$ & $(30)$ & $(10)$ & \\
\hline \multirow[t]{2}{*}{ Working conditions } & 19 & 8 & 5 & 30 & 18 & 3.25 \\
\hline & $(23.8)$ & $(10)$ & $(6.2)$ & $(37.5)$ & $(22.5)$ & \\
\hline \multirow[t]{2}{*}{ Attitude of co-workers } & 12 & 13 & 12 & 22 & 21 & 3.34 \\
\hline & $(15)$ & $(16.2)$ & (15) & $(27.5)$ & $(26.2)$ & \\
\hline Getting any appreciation for doing a & 5 & 11 & 2 & 25 & 37 & 3.98 \\
\hline good job & $(6.2)$ & $(13.8)$ & $(2.5)$ & $(31.2)$ & $(46.2)$ & \\
\hline Overall & & & & & & 3.38 \\
\hline
\end{tabular}

1 = strongly disagree, 2 = disagree, $3=$ neutral, $4=$ agree, $5=$ strongly agree; MAS = mean average score .

\subsection{Response towards Potential Turnover}

Identifying employees' perceptions about the potential turnover is important to assess the intentions and possibilities of employees' turnover. Table 3 shows the MAS values of different questions explaining the intention of employees to remain or leave the organizations. A large number of respondents agreed on the Likert scale that they would remain in the organization in the short run which indicates the positive perception about their job and the organization. However, the respondents noted that they intend to live the organization in the long run. For instance, $81.3 \%$ recorded that they intend to leave their current organization in the long run. Similarly, $71.2 \%$ noted that they were already interested in looking for a new job in the future. This shows that, though respondents were satisfied with their current job and organization, yet with experience, they were looking for the new organization and perhaps senior-level positions in other organizations. 
Table 3. Employees' Perception Regarding Turnover.

\begin{tabular}{|c|c|c|c|c|c|c|}
\hline \multirow[t]{2}{*}{ Item } & \multicolumn{5}{|c|}{ Employee perception } & \multirow[t]{2}{*}{ MAS } \\
\hline & 1 & 2 & 3 & 4 & 5 & \\
\hline $\begin{array}{l}\text { I intend to remain in this job in } \\
\text { the short run }\end{array}$ & $\begin{array}{c}5 \\
(6.2)\end{array}$ & $\begin{array}{c}22 \\
(27.5)\end{array}$ & $\begin{array}{c}7 \\
(8.8)\end{array}$ & $\begin{array}{c}32 \\
(40)\end{array}$ & $\begin{array}{c}14 \\
(17.5)\end{array}$ & 3.35 \\
\hline $\begin{array}{l}\text { I would like to remain in this } \\
\text { job in the short run }\end{array}$ & $\begin{array}{c}5 \\
(6.2)\end{array}$ & $\begin{array}{c}15 \\
(18.8)\end{array}$ & $\begin{array}{c}11 \\
(13.8)\end{array}$ & $\begin{array}{c}32 \\
(40)\end{array}$ & $\begin{array}{c}17 \\
(21.2)\end{array}$ & 3.51 \\
\hline $\begin{array}{l}\text { I intend to leave my job within } \\
\text { a year. }\end{array}$ & $\begin{array}{c}5 \\
(6.2)\end{array}$ & $\begin{array}{c}7 \\
(8.8)\end{array}$ & $\begin{array}{c}3 \\
(3.8)\end{array}$ & $\begin{array}{c}51 \\
(63.8)\end{array}$ & $\begin{array}{c}14 \\
(17.5)\end{array}$ & 3.78 \\
\hline $\begin{array}{l}\text { I will look for a new job in the } \\
\text { long run }\end{array}$ & $\begin{array}{c}11 \\
(13.8)\end{array}$ & $\begin{array}{c}5 \\
(6.2)\end{array}$ & $\begin{array}{c}7 \\
(8.8) \\
\end{array}$ & $\begin{array}{c}25 \\
(31.2)\end{array}$ & $\begin{array}{c}32 \\
(40) \\
\end{array}$ & 3.78 \\
\hline Overall & & & & & & 3.61 \\
\hline
\end{tabular}

1 = strongly disagree, 2 = disagree, $3=$ neutral, 4 = agree, 5 = strongly agree; MAS = mean average score.

\subsection{Effect of Job Satisfaction on Turnover}

The results of the regression model regarding the effects of job satisfaction on the turnover with organizational commitment as a moderating variable are provided in Table 4.

Table 4 shows that job satisfaction has a significant effect on turnover as shown by the $t$-value $=-6.734$ and $p<0.01$. So the null hypothesis that there is no significant relationship between job satisfaction and turnover is rejected. The negative sign of the coefficient shows that job satisfaction has an inverse relationship with turnover. If the job satisfaction level increases, the likelihood of turnover decreases and vice-versa. Similar findings were reported by Randhawa (2007) and Foreman (2009) who found a negative relationship between job satisfaction and turnover.

Table 4. Results of the Regression Model

\begin{tabular}{ccc}
\hline Name of Variables & B & t-ratio \\
\hline Job satisfaction (JS) & -.356 & $-6.734^{* * *}$ \\
Organizational commitment (OC) & -.457 & $-6.325^{* * *}$ \\
JS* OC (Moderating variable) & .013 & $4.936^{* * *}$ \\
Constant & 21.731 & 16.525 \\
F-value & 34.195 & \\
$\mathrm{R}^{2}$ & 0.574 &
\end{tabular}

Interaction of job satisfaction and organizational commitment also has a highly significant relationship with turnover as shown by a t-value of 4.936 and $\mathrm{p}<0.01)$. Therefore, the null hypothesis that organizational commitment is not significantly moderating the relationship between job satisfaction and turnover is rejected. The coefficient of the interaction of both has a positive sign which means that the moderator variable (organizational commitment) has a positive effect on turnover and job satisfaction. If there is less job satisfaction but high organizational commitment, then a low turnover may be expected because organizational commitment moderates the relation in a positive way. Maqbool et al., (2012) researched to check the moderation effect of organizational commitment on the relation of job satisfaction and turnover and found that organizational commitment moderated the relation. However, Yucel (2012) found a negative relationship between job satisfaction, organizational commitment, and turnover.

The R-square value shows that almost $57 \%$ of variation takes place in turnover because of job satisfaction, organizational commitment, and the interaction of job satisfaction and organizational commitment. The F-value is 34.195 with 3 degrees of freedom and a p-value less than 0.001 confirms that the overall model is highly significant 


\section{Conclusions and Recommendations}

This study was conducted to find out the relationship between job satisfaction and turnover. This study examined two telecommunication companies namely Wateen and Multinet telecom and primary data were collected from 140 randomly selected employees of these two companies. Five points Likert scale ranging from strongly dissatisfied to the strongly satisfied section was used to measure the variables. The study adopts a short version of the Minnesota satisfaction questionnaires to measure job satisfaction (Weiss et al., 1967) and a questionnaire developed by Foreman (2009) to measure the turnover. Cronbach alpha coefficient was used to check the reliability of the data and higher values than 0.70 for all attributes confirmed the reliability of data. The perception of respondents regarding their job satisfaction and turnover was determined by using the mean average score (MAS) which confirmed that independent, moderating, and dependent variables were related to each other. The relationship between job satisfaction and turnover was determined by using regression analysis. Results of the regression model show that job satisfaction is significantly related to turnover and that organizational commitment is exhibiting a significant effect on job satisfaction and turnover, as shown by $\mathrm{p}<0.01$. The paper concludes that organizations should make all possible efforts to keep their employees satisfied so that to reduce the turnover. The study recommends that management of the organization should take all those possible measures that increase job satisfaction, for instance, pays and other benefits. Similarly, management should also take measures to enhance the organizational commitment of the employees, for example, pieces of training, exposures, and opportunities for promotion. These measures will help in increasing job satisfaction and organizational commitment, and thereby, would reduce turnover.

Author Contributions: The article is based on the MS Management Sciences thesis of H.W supervised by I.J.

Funding: This research received no external funding.

Conflicts of Interest: The authors declare that they do not have any conflict of interest.

\section{References}

Ahmad, B., Shahid, M., Huma, Z., \& Haider, S. (2012). Turnover intention: An HRM issue in the textile sector. Interdisciplinary Journal of Contemporary Research in Business, 3(12), 125-130.

Cotton, J., \& Tuttle, J. (1986). Employee turnover: a meta-analysis and review with implication for research. Academy of Management Review, 11(1), 55-70.

Foreman, T.W. (2009). Job satisfaction and turnover in the Chinese retail industry. Chinese Management Studies, 3(4), $356-378$.

Griffeth, R.W., Hom, P.W., \& Gaertner, S. (2000). A meta-analysis of antecedents and correlates of employee turnover: update, moderator tests, and research implications for the next millennium. Journal of Management, 26(3), 463-488.

Hair, J.F., Black, W.C., Babin, B.J., Anderson, R.E., \& Tatham, R.L. (2010). Multivariate data analysis, 7th ed., Prentice-Hall, Upper Saddle River, NJ.

Hayes, L.J., O’Brien, P.L., Duffield, C., Shamian, J., Buchan, J., Hughes, F., Laschinger, H.K.S., North, N., \& Stone, P.W. (2006). Nurse turnover: a literature review. International Journal of Nursing Studies, 43(2), 237-263.

Hung, L-M., Lee, Y-S., Lee, D-C. (2018). The moderating effects of salary satisfaction and working pressure on the organizational climate, organizational commitment to turnover intention.International Journal of Business and Society, 19(1), 103-116.

Kaplan, D. (2009). Determinants of job satisfaction and turnover among physicians (Thesis). San Jose State University, California, United States.

Kinicki, A.J., Mckee, F.M.R., Schriesheim, C.A., \& Carson, K.P. (2002). Assessing the construct validity of the job descriptive index: a review and meta-analysis. Journal of Applied Psychology, 87(1), 14-32.

Lin, C-Y., \& Huang, C-K. (2020). Employee turnover intentions and job performance from a planned change: the effects of an organizational learning culture and job satisfaction. International Journal of Manpower, 01437720. https://doi 10.1108/IJM-08-2018-0281. 
Locke, E.A. (1976). The nature and cause of job satisfaction. In M.D. Dunnette (Ed.), Handbook of Industrial and Organizational Psychology, 1300. Chicago: Rand-Mcnally.

Mowday, R.T., Porter, L.W., \& Steers, R.M. (1979). The measurement of organizational commitment. Journal of Vocational Behavior, 14(2), 224-247.

Mudor, H., \& Tooksoon, P. (2011). Conceptual framework on the relationship between human resource management practices, job satisfaction, and turnover. Journal of Economics and Behavioral Studies, 2(2), 41-49.

Obiechina, B.T. (2019). The relationship between organizational commitment and turnover intention: the moderation effect of constituent attachment.

Romeo, M., Yepes-Baldó, M., \& Lins, C. (2020). Job satisfaction and turnover intention among people with disabilities working in Special Employment Centers: The moderation effect of organizational commitment. Frontiers in Psychology, 11(1035).

Tubay, J.B. (2019). The role of job satisfaction and organizational commitment on turnover intentions of accounting professionals in big 3 auditing firms in the Philippines with the moderating effect of leadermember exchange. International Review of Management and Marketing, 9(2), 84-88.

Wang, Q., \& Wang, C. (2020). Reducing turnover intention: perceived organizational support for frontline employees. Frontiers of Business Research in China,14(6).

Weiss, D.J., Dawis, R.V., England, G.W., \& Lofquist, L.H. (1967). Manual for the Minnesota satisfaction questionnaire. Minneapolis: University of Minnesota, Industrial Relation Center.

Wright, T.A., \& Bonett, D.G. (2007). Job satisfaction and psychological well-being as no additive predictors of workplace turnover. Journal of Management, 33(2), 141-252.

(C) 2020 by the authors. This article is an open-access article distributed under the terms and conditions of the Creative Commons Attribution (CC BY) license (http://creativecommons.org/licenses/by/4.0/). 